OPEN ACCESS

Edited by:

Qingxin Mu,

University of Washington, United States

Reviewed by:

Xiangbing Meng,

The University of lowa, United States Jeni Prosperi,

Indiana University School of Medicine,

United States

*Correspondence:

Manoj Baranwal

manoj.baranwal@thapar.edu orcid.org/0000-0002-6581-9346

Specialty section:

This article was submitted to

Cancer Molecular Targets and

Therapeutics,

a section of the journal

Frontiers in Oncology

Received: 26 February 2019 Accepted: 15 April 2019

Published: 03 May 2019

Citation:

Dhiman G, Srivastava N, Goyal M, Rakha E, Lothion-Roy J, Mongan NP,

Miftakhova RR, Khaiboullina SF,

Rizvanov AA and Baranwal M (2019)

Metadherin: A Therapeutic Target in

Multiple Cancers. Front. Oncol. 9:349.

doi: 10.3389/fonc.2019.00349

\section{Metadherin: A Therapeutic Target in Multiple Cancers}

\author{
Gourav Dhiman ${ }^{1}$, Neha Srivastava ${ }^{1}$, Mehendi Goyal ${ }^{1}$, Emad Rakha ${ }^{2}$, \\ Jennifer Lothion-Roy ${ }^{3}$, Nigel P. Mongan ${ }^{3}$, Regina R. Miftakhova ${ }^{4}$, \\ Svetlana F. Khaiboullina ${ }^{4,5}$, Albert A. Rizvanov ${ }^{4}$ and Manoj Baranwal ${ }^{1 *}$ \\ ${ }^{1}$ Department of Biotechnology, Thapar Institute of Engineering and Technology, Patiala, India, ${ }^{2}$ Faculty of Medicine and \\ Health Sciences, School of Medicine, University of Nottingham, Nottingham, United Kingdom, ${ }^{3}$ Faculty of Medicine and \\ Health Sciences, School of Veterinary Medicine and Science, University of Nottingham, Nottingham, United Kingdom, \\ ${ }^{4}$ Institute of Fundamental Medicine and Biology, Kazan Federal University, Kazan, Russia, ${ }^{5}$ Department of Microbiology and \\ Immunology, University of Nevada, Reno, NV, United States
}

Altered expression of many genes and proteins is essential for cancer development and progression. Recently, the affected expression of metadherin (MTDH), also known as AEG-1 (Astrocyte Elevated Gene 1) and Lyric, has been implicated in various aspects of cancer progression and metastasis. Elevated expression of MTDH/AEG-1 has been reported in many cancers including breast, prostate, liver, and esophageal cancers, whereas its expression is low or absent in non-malignant tissues. These expression studies suggest that MTDH may represent a potential tumor associated antigen. MTDH also regulates multiple signaling pathways including PI3K/Akt, NF-кB, Wnt/ $\beta$-catenin, and MAPK which cooperate to promote the tumorigenic and metastatic potential of transformed cells. Several microRNA have also been found to be associated with the increased MTDH expression in different cancers. Increased MTDH levels were linked to the tumor chemoresistance making it an attractive novel therapeutic target. In this review, we summarize data on MTDH function in various cancers.

Keywords: metadherin, chemoresistance, microRNA, immunotherapy, cancer

\section{INTRODUCTION}

Advances in cancer prevention and early diagnosis significantly improved the cancer treatment outcomes. Still, cancers remain one of the most challenging global healthcare. Approximately 18 million new cancer cases and 9.6 million malignancy related deaths were expected in 2018 (1). One of the major challenges in cancer therapy is its specificity, where only cancers become affected without injuring the healthy cells. Therefore, advances in identification of tumor antigens are essential for targeting exclusively tumor cells. Tumor antigens are classified as tumor specific, tumor associated and cancer testis antigens (2). Tumor associated antigens (TAA) are over-expressed in tumors and these can be used as immunotherapeutic targets. In the effort of identification of this targets, 15 Astrocyte Elevated Genes have been characterized, of which metadherin (MTDH) was shown to be the most relevant to tumorigenesis. MTDH, also known as Astrocyte Elevated Gene-1(AEG-1) or LYRIC (Lysine Rich CEACAM1), is a putative TAA (3-5). MTDH was identified by in vivo phage display screening as a protein which was responsible for the breast to lung cancer metastasis possessing extracellular domain called lung homing domain (4). Further investigations revealed MTDH expression in various cancer types capable of metastasis (3-5). 
There are two MTDH isoforms coded on chromosome eight. Amplification of $8 \mathrm{q} 22$, including the $\mathrm{MTDH}$ locus is associated with chemoresistance and metastasis in aggressive breast cancer (6). Multiple cancer associated mutations in the MTDH gene (Figure 1A) are reported in the COSMIC database (7). Furthermore, altered expression, copy number and mutations of MTDH (Figure 1B) have been identified in many cancer types as reported in the cBIO database (8). There is increasing evidence in functional interactions of MTDH and important pro-oncogenic pathways, including MYC-mediated processes (Figure 2). It appears that the main role of $\mathrm{MTDH}$ is associated with tumor chemoresistance and metastasis (6). Here we present an overview of the MTDH expression and function in various cancers as well as its potential as an intrinsic treatment modulating agent.

\section{MTDH REGULATION AND MOLECULAR FUNCTIONS}

MTDH is a type-two transmembrane protein containing an extracellular lung homing domain which is implicated in breast cancer metastasis to the lung (4). MTDH encodes a single-pass transmembrane protein with the molecular mass of $64-\mathrm{kDa}$ expressed mainly in the endoplasmic reticulum and perinuclear space (5). In polarized epithelial cells, it colocalizes with tight junction protein $\mathrm{ZO}-1$ and occludin (3); however $\mathrm{MTDH}$ is not a native component of tight junctions but become incorporated during tight junction complex maturation. The sub-cellular location of MTDH protein varies depending upon physiological state of the cell (9). In non-malignant tissue, MTDH was shown expressed in the nucleus, whereas in

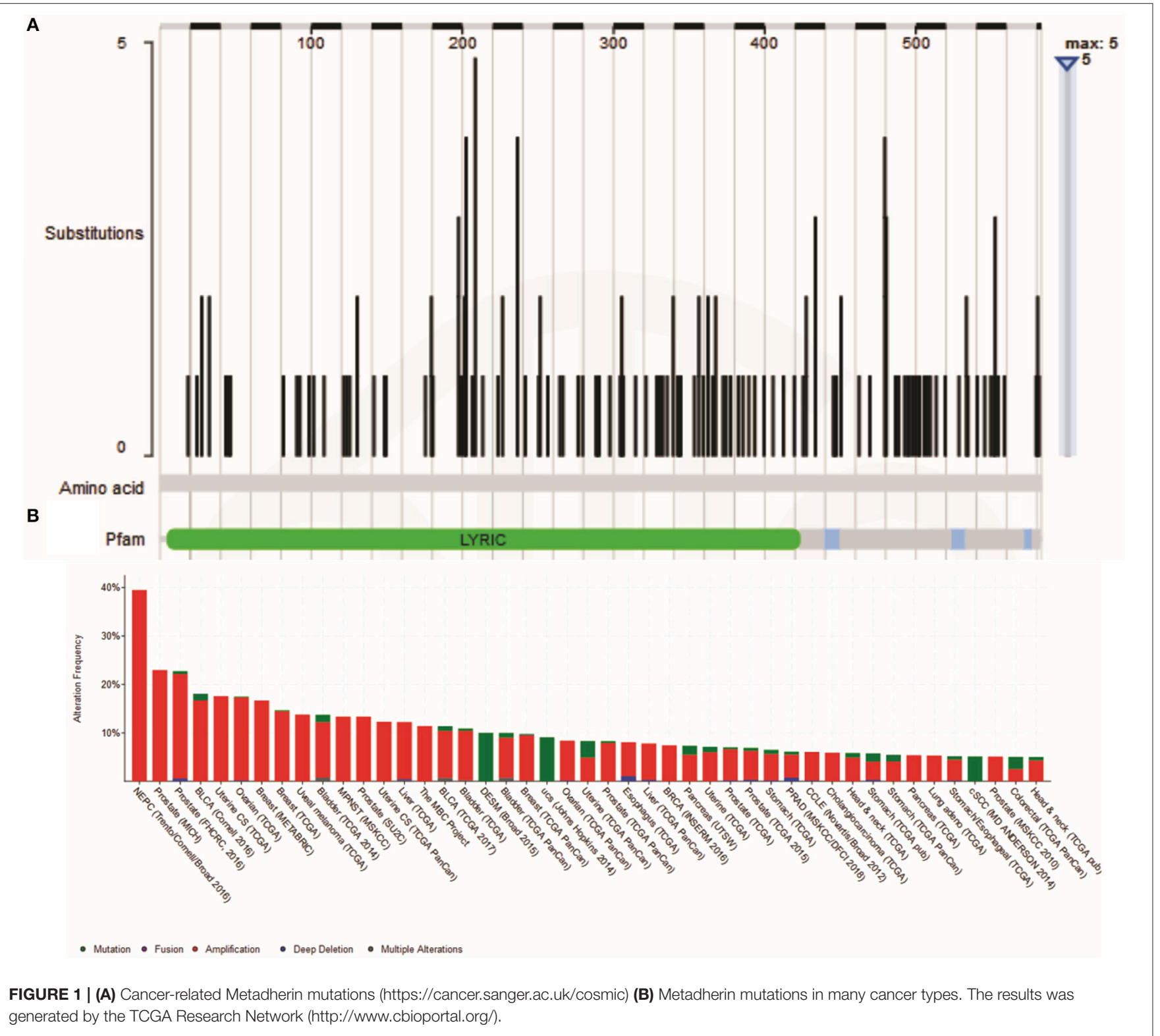




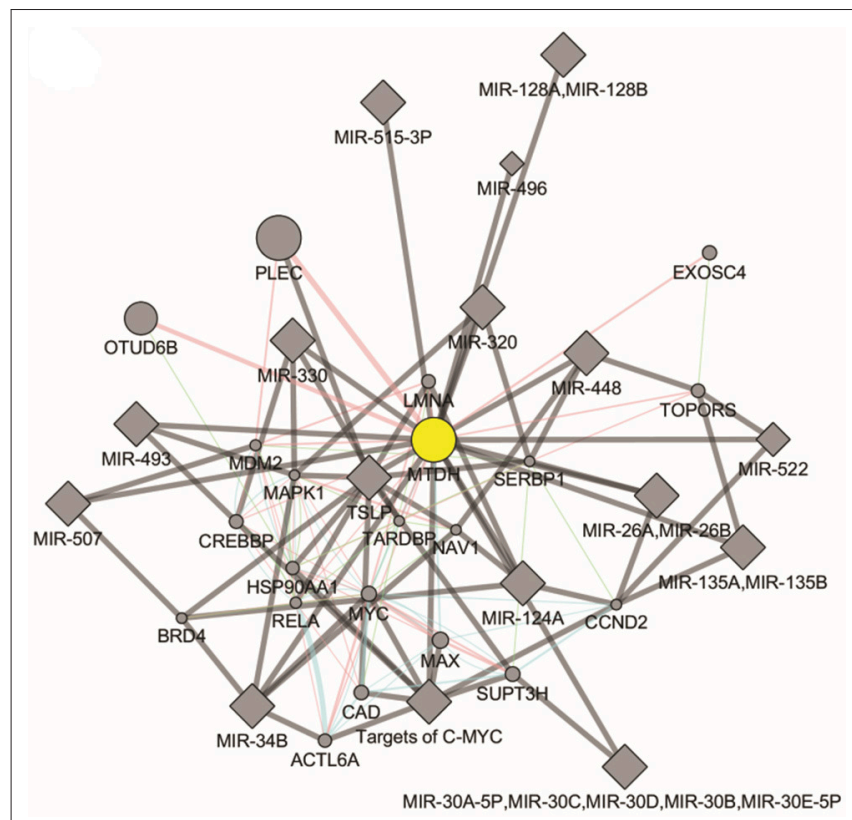

FIGURE 2 | Molecular pathways of Metadherin generated by GeneMANIA Cytoscape plugin (https://genemania.org/).

malignant cells it becomes translocated into the cytoplasm (10). It is believed that cytoplasmic translocation of MTDH promotes disease progression by mediating mechanisms that support proangiogenesic and metastatic pathways.

It appears that TNF- $\alpha$ is the key regulator of $\mathrm{MTDH}$ expression. TNF- $\alpha$ upregulates MTDH expression via NF$\kappa \mathrm{B}$ pathways. TNF- $\alpha$ causes NF- $\kappa \mathrm{B}$ nuclear translocation and consequent interaction with MTDH, which is essential for activation of downstream genes (11). The N-terminal domain of MTDH interacts with NF- $\mathrm{B}$ and triggers gene expression via several convergent mechanisms (9). NF- $\kappa \mathrm{B}$ nuclear translocation coincides with a significant reduction of $\mathrm{I} \kappa \mathrm{B} \alpha$ level, suggesting MTDH involvement in $I \kappa B \alpha$ degradation. Studies have also revealed that $\mathrm{MTDH}$ interacts with Cyclic AMP-responsive element binding protein-binding protein (CBP) which is a NF- $\kappa \mathrm{B}$ coactivator $(9,12)$. Hence, MTDH may function as a bridging element among p50-p65, NF- $\mathrm{B}, \mathrm{CBP}$, and the basal transcription machinery and therefore consequent induction of $\mathrm{NF}-\kappa \mathrm{B}$ related gene expression enhances migration and invasion (9) (Figure 3). MTDH promoted NF- $\kappa$ B gene expression results in anchorage independent cell growth (10), possibly mediated by direct activation of matrix metalloproteinase 1 (MMP1) expression (13). MTDH also serves as a link between NF$\kappa \mathrm{B}$ and matrix metalloprotease 9 (MMP9) expression (14, 15).The role of MTDH/AEG-1 as an endoplasmic reticulum (ER)-associated cytoplasmic RNA binding protein has been recently reported by Meng et al. (16) where MTDH/AEG-1 was also found in complex with other RNA binding proteins. More recently $\mathrm{Hsu}$ et al. (17) identified the MTDH/AEG1: RNA interactome using unbiased genome wide methods including HITS-CLIP (high-throughput sequencing of RNA isolated by crosslinking immunoprecipitation) and PAR-CLIP (photoactivatable ribonucleoside-enhanced crosslinking and immunoprecipitation) which revealed that the MTDH/AEG1 RNA interactome includes the organelle protein-encoding transcripts as well as secretory and cytosolic protein-encoding mRNAs (17).

\section{MTDH EXPRESSION AND FUNCTION IN CANCER}

MTDH is involved in multiple cancer associated cellular signaling pathways, most notably in the context of this review, pro-angiogenesis and pro-metastasis pathways (Figure 3, Table 1). MTDH/AEG-1 promotes cell survival, inhibits apoptosis, and promotes tumor progression via multiple PI3K/Akt pathways (18). Emdad et al. (19) further showed that MTDH/AEG-1 promotes an invasive phenotype and angiogenesis via PI3K-Akt. The potential role of MTDH in angiogenesis is related to its functional link to vascular endothelial growth factor (VEGF), IGFBP7, and epithelialmesenchymal transition (EMT) markers. It was shown that MTDH increases VEGF expression via the PI3K/Akt pathway in head and neck squamous cell (20). MTDH is also associated with expression of the E-cadherin, $\beta$-catenin, snail, and $\mathrm{N}$ cadherin epithelial-mesenchymal transition (EMT) markers in hepatocellular carcinoma cells (21). There is also evidence of a functional link between $\mathrm{MTDH}$ and pro-survival mechanisms mediated by the lymphoid enhancer binding factor 1 (LEF1) and GSK3 $\beta$ components of the $\mathrm{Wnt} / \beta$-catenin pathway in chronic lymphocytic leukemia (22) and hepatocellular carcinoma (23). Elevated expression of MTDH in hepatocellular carcinoma results in the up-regulation of multiple genes and signaling pathways such as the activation of ERK 42/44 and p38 Mitogen Activated Protein Kinase (MAPK) signaling pathway (24). Activation of ERK 42/44 and p38 MAPK enhanced GSK3 $\beta$ phosphorylation which in turn drives $\beta$-catenin nuclear translocation and thereby activate Wnt signaling (24).

Also, MTDH/AEG-1 can up regulate Claudin 4 (CLDN4) and tetraspanin which enhance cell invasion (23). Chen et al. have shown that the increased expression of MTDH/AEG-1 frequently overserved in hepatocellular carcinoma downregulates expression of the IGFB7 tumor suppressor and thereby contributes to cancer progression (25). It has also been shown that the knockdown of MTDH causes increased sensitivity to Panobinostat (LBH589) and tumor necrosis factor-a-related apoptosis-inducing ligand (TRAIL) combination treatment. As TRAIL can trigger apoptosis in cancer cells and LBH589 augments the sensitivity of cancer cells to TRAIL induced apoptosis. It can be inferred that over expression of MTDH may negatively influence apoptosis and cell cycle checkpoints and thereby promote cell survival (26).

\section{CLINICAL SIGNIFICANCE OF MTDH EXPRESSION IN CANCER}

MTDH was shown to be expressed in ductal carcinoma in situ (DCIS) of the breast (27). Increased MTDH expression 


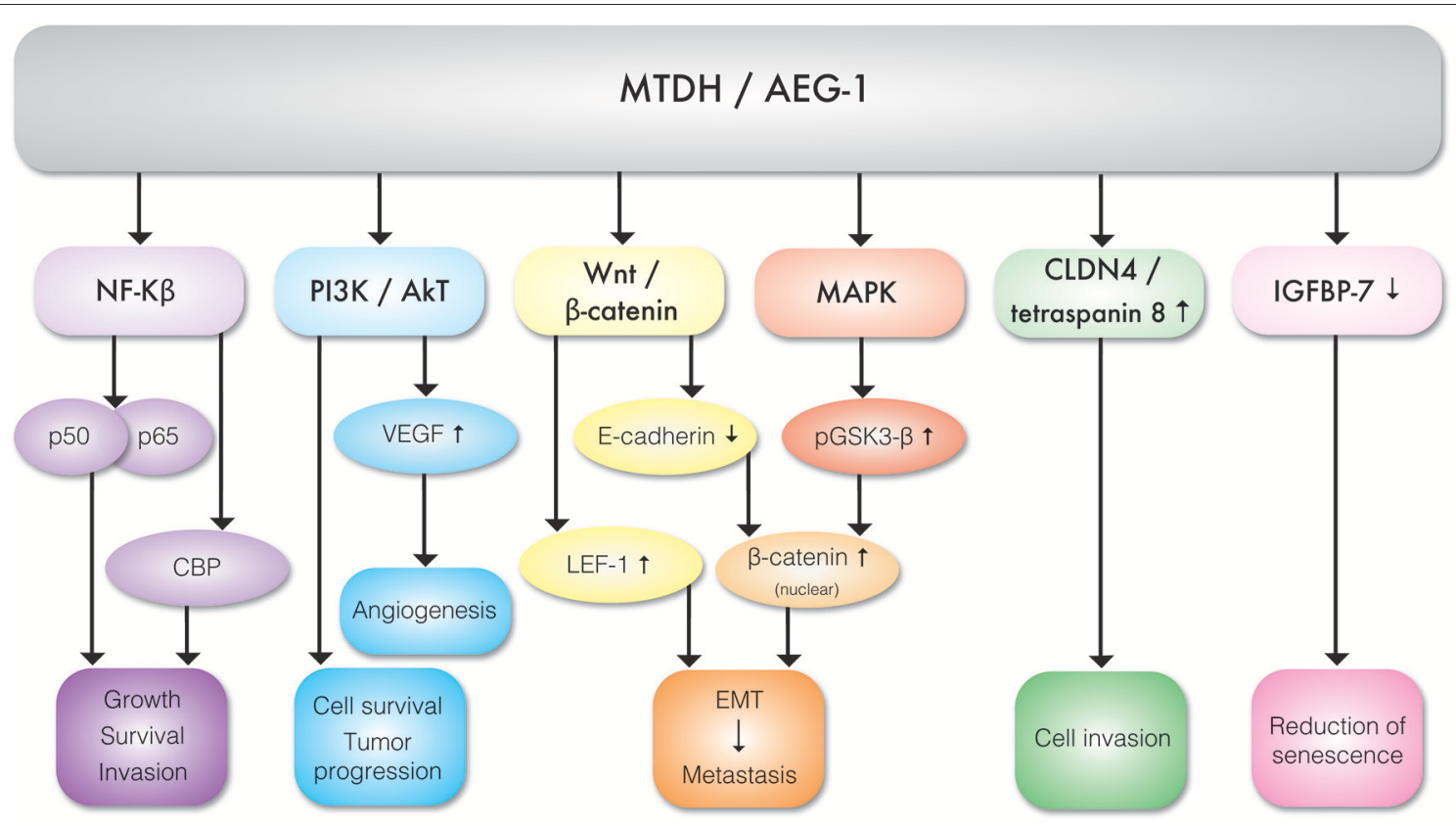

FIGURE 3 | Molecular interactions between MTDH/AEG-1 and various effector molecules of signal transduction pathways exhibiting different biological functions.

is also implicated in prostate cancer $(10,28)$. Also MTDH functionally interacts with the Ha-Ras oncogene and leads to tumor development and progression in melanocytes (5). Expression of $\mathrm{MTDH}$ is implicated in breast cancer stem cell (CSC) growth and tumor resistance to paclitaxel and trastuzumab (29-32). Elevated expression of MTDH was also reported in salivary gland tumors and is associated with poorer outcomes (33). Increased expression of MTDH is also implicated in hepatocellular carcinoma recurrence and metastasis which remains one of five most commonly diagnosed cancers worldwide, largely attributable to chronic viral hepatitis (HBV, HCV), and alcoholism (20, 34-36). Increased MTDH expression is also associated with mechanisms of metastasis in colorectal cancer (CRC) $(15,37)$ including activation of MMP9. Increased MTDH is also associated with AKT/PI3K mediated mechanisms of metastasis in head and neck squamous cell carcinoma (HNSCC) patients (38). The significance of MTDH regulation of cancer growth was confirmed using miRNA375 and MTDH knockdown experiments in HNSCC model (35). MTDH can regulate the cancer cell metastasis by actin cytoskeletal remodeling in gastric and non-small cell lung cancer $(39,40)$. Accordingly, the downregulation of MTDH expression could induce remodeling of the actin cytoskeleton and inhibit epithelial-mesenchymal transition in gastric cancer cell lines (MKN45 and AGS) (39).

\section{ROLE OF INCREASED MTDH EXPRESSION IN TREATMENT RESISTANCE}

Many mechanisms of anticancer drug resistance have been described in cancer cells and have been reviewed elsewhere recently $(41,42)$. There is a strong evidence linking MTDH expression to the resistance to multiple cancer therapeutics, including tamoxifen, trastuzumab, and paclitaxel $(6,16,30,31$, 43, 44).Chemo-resistance in MTDH expressing cells was shown associated with activation of autophagy. Autophagy related mechanisms were shown to protect tumor cells from metabolic stress caused by the anticancer drugs cisplatin and paclitaxel (45). Experimental suppression of MTDH lead to an increased sensitivity to doxorubicin in cancer cells (46-48). These MTDH targeting therapeutic approaches could applied not only to treat cancer, but also to prevent, reverse or delay the chemo resistance.

\section{MICRO RNAS REGULATION OF MTDH EXPRESSION}

It is well-established that micro-RNAs (miRs) play important, if subtle, roles in the regulation of gene expression and translation in cellular differentiation and proliferation. Unsurprisingly, aberrant expression of oncogenic miRs (onco-miRs) and tumor suppressor miRs is implicated in cancer pathogenesis $(49,50)$. MTDH regulates expression of miRs and in turn is also regulated by miRs (Figure 4). MTDH knockdown inhibits angiogenetic properties of the MDA-MB-231 breast cancer cell line, which is mediated by downregulation of the oncomir $m i R-21$ (51). In contrast, reduction in $m i R-630$ expression results in increased MTDH expression in breast cancer (52) (Figure 4). Expression of miR-145 is lost in high-grade serous ovarian carcinoma resulting in an increased expression of MTDH (53) (Figure 4). Loss of activity of the p53 tumor suppressor results in decreased or loss of miR-145 expression, contributing to an increased MTDH levels (53). Similarly, miR-342-3p functions as a tumor 
suppressor by targeting MTDH in human osteosarcoma (54) and prostate cancer (55). Expression of $m i R-26 a$ regulates $\mathrm{MTDH}$

TABLE 1 | MTDH containing gene ontologies.

\section{GENE ONTOLOGIES}

\section{Molecular Functions}

GO:0000988:transcription factor activity, protein binding

GO:0000989:transcription factor activity, transcription factor binding

GO:0001085:RNA polymerase II transcription factor binding

GO:0003712:transcription cofactor activity

GO:0003713:transcription coactivator activity

GO:0003723:RNA binding

GO:0003725:double-stranded RNA binding

GO:0008134:transcription factor binding

GO:0044822:poly(A) RNA binding

GO:0051059:NF-kappaB binding

\section{Cellular Components}

GO:0005635:nuclear envelope

GO:0005923:bicellular tight junction

GO:0016324:apical plasma membrane

GO:0016604:nuclear body

GO:0031965:nuclear membrane

GO:0043296:apical junction complex

GO:0045177:apical part of cell

GO:0046581:intercellular canaliculus

GO:0048471:perinuclear region of cytoplasm

GO:0070160:occluding junction

\section{Molecular Functions}

GO:0007043:cell-cell junction assembly

GO:0010508:positive regulation of autophagy

GO:0031663:lipopolysaccharide-mediated signaling pathway

GO:0043297:apical junction assembly

GO:0045766:positive regulation of angiogenesis

GO:0051092:positive regulation of NF-kappaB transcription factor activity

GO:0051896:regulation of protein kinase B signaling

GO:0051897:positive regulation of protein kinase B signaling

GO:0070830:bicellular tight junction assembly

GO:1904018:positive regulation of vasculature development levels, where the loss of miR-26a in triple negative breast cancer cells (TNBC) leads to increased MTDH and acts as a prognostic marker for breast cancer outcome (56) (Figure 4). Similarly, upregulation of MTDH in gastric cancer may occur as a consequence of reduced $m i R-22$ expression. Moreover, $m i R$ 22 can prevent gastric cancer cell proliferation and invasion, suggesting its potential therapeutic efficacy (57) (Figure 4). Thus, it can be concluded that miRNAs are crucially involved in regulation of MTDH expression in malignancies.

\section{MTDH AS A POTENTIAL TARGET FOR CANCER THERAPEUTICS}

MTDH plays an important role in progression and metastasis of many cancers. Although the understanding of the MTDH cancer promoting mechanisms is incomplete, there is a compelling evidence that MTDH regulates multiple signaling pathways which cooperate to promote the tumorigenic and metastatic potential of transformed cells. Additionally there is new evidence suggesting that functional inhibition of MTDH function could be the novel approach to treat cancer. For example, MTDH in breast cancer down regulates expression of the PTEN (Phosphatase and tensin homolog) tumor suppressor via NF- $\kappa B$ mediated pathways and contributes to the HER2targeting therapy resistance (31). Thus, MTDH may represent an interesting therapeutic target for treatment of HER2+ breast cancers. For example, Bortezomib, is an FDA-approved proteasome inhibitor used in multiple myeloma treatment and acts (in part) by reducing MTDH activity (58). Studies have further demonstrated that RNAi-mediated knockdown of MTDH reduces angiogenesis by down regulating the ERK1/2 signaling (51).

Immunotherapy targeting the tumor antigens has been an area of intense research. Expression of MTDH is increased in many different cancer types. Importantly, auto-antibodies against the MTDH protein have been detected in cancer patients confirming its immunogenicity and supports MDTH as a potential immunotherapy target (59). We recently identified

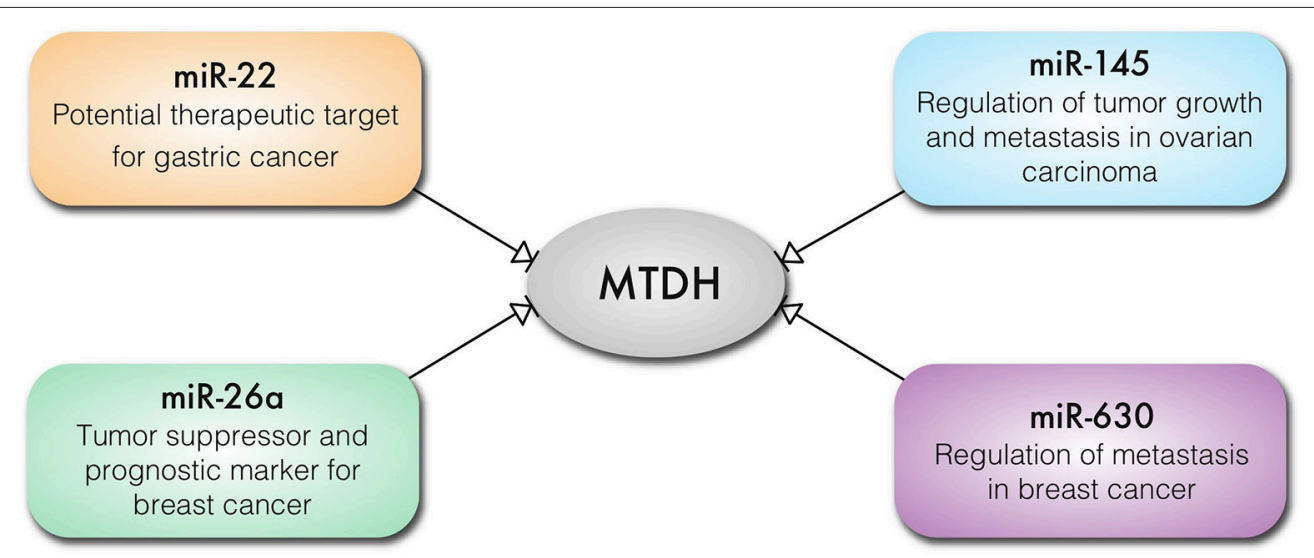

FIGURE 4 | Key cancer related miRNAs that regulate the expression of MTDH in different types of cancer cells. 
three T-cell epitopes within the MTDH protein supporting its potential value as a cancer vaccine target (60). Consistent with this a DNA vaccine designed to induce an anti-MTDH CD8 ${ }^{+}$ mediated immune response inhibited cancer cell proliferation and lung metastases in a mouse breast cancer xenograft model (47). Given that MTDH/AEG-1 expression is increased in many cancer types and proof of principle experiments support it as an effective immunotherapy target, further research is now warranted to test such treatments efficacy in advanced preclinical cancer models.

\section{CONCLUSION}

MTDH is pro-oncogenic factor playing multifaceted and diverse roles in cancer progression. Its association and central role in regulating signaling pathways such a MAPK, wnt $/ \beta$-catenin, $\mathrm{PI} 3 \mathrm{~K} / \mathrm{AkT}, \mathrm{NF}-\kappa \beta$ pathways in various cancers shows that it plays a vital role in metastasis. MTDH contribution to chemo and radiotherapy resistance provides a new direction for the development of anticancer therapeutics. Multiple mechanisms converge to promote expression of MTDH in cancers. Further studies are therefore warranted to determine whether the elevated MTDH expression has prognostic value for development of the malignancy. Given its increased expression in many cancer types it would be important to determine whether MTDH represents a feasible target for cancer therapy, including

\section{REFERENCES}

1. Bray F, Ferlay J, Soerjomataram I, Siegel RL, Torre LA, Jemal A. Global cancer statistics 2018: GLOBOCAN estimates of incidence and mortality worldwide for 36 cancers in 185 countries. CA Cancer J Clin. (2018) 68:394-424. doi: $10.3322 /$ caac. 21492

2. Yarchoan M, Johnson BA III, Lutz ER, Laheru DA, Jaffee EM. Targeting neoantigens to augment antitumour immunity. Nat Rev Cancer. (2017) 17:209. doi: 10.1038/nrc.2016.154

3. Britt DE, Yang D-F, Yang D-Q, Flanagan D, Callanan H, Lim Y$\mathrm{P}$, et al. Identification of a novel protein, LYRIC, localized to tight junctions of polarized epithelial cells. Exp Cell Res. (2004) 300:134-48. doi: 10.1016/j.yexcr.2004.06.026

4. Brown DM, Ruoslahti E. Metadherin, a cell surface protein in breast tumors that mediates lung metastasis. Cancer Cell. (2004) 5:365-74. doi: 10.1016/S1535-6108(04)0079-0

5. Kang D-C, Su Z-Z, Sarkar D, Emdad L, Volsky DJ, Fisher PB. Cloning and characterization of HIV-1-inducible astrocyte elevated gene-1, AEG-1. Gene. (2005) 353:8-15. doi: 10.1016/j.gene.2005.04.006

6. Hu G, Chong RA, Yang Q, Wei Y, Blanco MA, Li F, et al. MTDH activation by $8 \mathrm{q} 22$ genomic gain promotes chemoresistance and metastasis of poor-prognosis breast cancer. Cancer Cell. (2009) 15:9-20. doi: 10.1016/j.ccr.2008.11.013

7. Forbes SA, Beare D, Boutselakis H, Bamford S, Bindal N, Tate J, et al. COSMIC: somatic cancer genetics at high-resolution. Nucleic Acids Res. (2017) 45:D77783. doi: 10.1093/nar/gkw1121

8. Cerami E, Gao J, Dogrusoz U, Gross BE, Sumer SO, Aksoy BA, et al. The cBio cancer genomics portal: an open platform for exploring multidimensional cancer genomics data [Research Support, N.I.H., Extramural Research Support, Non-U.S. Gov't]. Cancer Discov. (2012) 2:401-4. doi: 10.1158/2159-8290.CD-12-0095

9. Sarkar D, Park ES, Emdad L, Lee S-G, Su Z-Z, Fisher PB. Molecular basis of nuclear factor- $\mathrm{B}$ activation by astrocyte elevated gene-1. Cancer Res. (2008) 68:1478-84. doi: 10.1158/008-5472.CAN-07-6164 immune-therapy. For these reasons there is now an urgent need to determine the clinical and therapeutic significance of increased MTDH expression in cancer.

\section{AUTHOR CONTRIBUTIONS}

GD originated the idea for writing the review and wrote about MTDH association in different cancers. NS and MG wrote the following sections: micro RNAs regulation of $\mathrm{MTDH}$ expression and MTDH target for cancer therapy. ER, JL-R, and NM were involved in writing the MTDH regulation and molecular functions and preparing the original figures. RM and SK contributed to the clinical significance of MTDH expression in cancer. AR managed the different collaborations during the writing of the review and contributed to editing the manuscript. $\mathrm{MB}$ was overall responsible for coordinating and managing multisite collaboration, and writing the manuscript.

\section{ACKNOWLEDGMENTS}

$\mathrm{AR}$ and SK were getting support from the Russian Government Program of Competitive Growth of Kazan Federal University. AR was personally getting support by state assignment 20.5175.2017/6.7 of the Ministry of Education and Science of Russian Federation.

10. Thirkettle HJ, Girling J, Warren AY, Mills IG, Sahadevan K, Leung H, et al. LYRIC/AEG-1 is targeted to different subcellular compartments by ubiquitinylation and intrinsic nuclear localization signals. Clin Cancer Res. (2009) 15:3003-13. doi: 10.1158/1078-0432.CCR-08-2046

11. Emdad L, Sarkar D, Su Z-Z, Randolph A, Boukerche H, Valerie $\mathrm{K}$, et al. Activation of the nuclear factor $\kappa \mathrm{B}$ pathway by astrocyte elevated gene-1: implications for tumor progression and metastasis. Cancer Res. (2006) 66:1509-16. doi: 10.1158/008-5472.CAN-053029

12. Huang W-C, Ju T-K, Hung M-C, Chen C-C. Phosphorylation of CBP by IKK $\alpha$ promotes cell growth by switching the binding preference of CBP from p53 to NF-кB. Mol Cell. (2007) 26:75-87. doi: 10.1016/j.molcel.2007. 02.019

13. Wang Y-P, Liu I-J, Chiang C-P, Wu H-C. Astrocyte elevated gene-1 is associated with metastasis in head and neck squamous cell carcinoma through p65 phosphorylation and upregulation of MMP1. Mol Cancer. (2013) 12:109. doi: 10.1186/1476-459812-109

14. Huang L-L, Wang Z, Cao C-J, Ke Z-F, Wang F, Wang R, et al. AEG-1 associates with metastasis in papillary thyroid cancer through upregulation of MMP2/9. Int J Oncol. (2017) 51:812-22. doi: 10.3892/ijo. 2017.4074

15. Song $\mathrm{H}$, Tian Z, Qin Y, Yao G, Fu S, Geng J. Astrocyte elevated gene-1 activates MMP9 to increase invasiveness of colorectal cancer. Tumour Biol. (2014) 35:6679-85. doi: 10.1007/s13277-0141883-3

16. Meng X, Zhu D, Yang S, Wang X, Xiong Z, Zhang Y, et al. Cytoplasmic Metadherin (MTDH) provides survival advantage under conditions of stress by acting as RNA-binding protein. J Biol Chem. (2012) 287:4485-91. doi: 10.1074/jbc.C111.291518

17. Hsu JC, Reid DW, Hoffman AM, Sarkar D, Nicchitta CV. Oncoprotein AEG-1 is an endoplasmic reticulum RNA-binding protein whose interactome is enriched in organelle resident protein-encoding mRNAs. RNA. (2018) 24:688-703. doi: 10.1261/rna.063313.1171 
18. Lee SG, Su ZZ, Emdad L, Sarkar D, Franke TF, Fisher PB. Astrocyte elevated gene-1 activates cell survival pathways through PI3K-Akt signaling. Oncogene. (2008) 27:1114.doi: 10.1038/sj.onc.1210713

19. Emdad L, Lee SG, Su ZZ, Jeon HY, Boukerche H, Sarkar D, et al. Astrocyte elevated gene-1 (AEG-1) functions as an oncogene and regulates angiogenesis. Proc Natl Acad Sci USA. (2009) 106:21300-5. doi: 10.1073/pnas. 0910936106

20. Zhu G-C, Yu C-Y, She L, Tan H-L, Li G, Ren S-L, et al. Metadherin regulation of vascular endothelial growth factor expression is dependent upon the PI3K/Akt pathway in squamous cell carcinoma of the head and neck. Medicine. (2015) 94:502. doi: 10.1097/MD.0000000000000502

21. Zhu K, Dai Z, Pan Q, Wang Z, Yang G-H, Yu L, et al. Metadherin promotes hepatocellular carcinoma metastasis through induction of epithelial-mesenchymal transition. Clin Cancer Res. (2011) 17:7294-302. doi: 10.1158/1078-0432.CCR-11-1327

22. Li PP, Feng LL, Chen N, Ge XL, Lv X, Lu K, et al. Metadherin contributes to the pathogenesis of chronic lymphocytic leukemia partially through Wnt/ $\beta$ catenin pathway. Med Oncol. (2015) 32:479. doi: 10.1007/s12032-014-0479-5

23. Yoo BK, Emdad L, Su Z-Z, Villanueva A, Chiang DY, Mukhopadhyay ND, et al. Astrocyte elevated gene-1 regulates hepatocellular carcinoma development and progression. J Clin Invest. (2009) 119:465-77. doi: 10.1172/JCI36460

24. Shi X, Wang X. The role of MTDH/AEG-1 in the progression of cancer. Int $J$ Clin Exp Med. (2015) 8:4795-807.

25. Chen D, Yoo BK, Santhekadur PK, Gredler R, Bhutia SK, Das SK, et al. Insulin-like growth factor binding protein-7 (IGFBP7) functions as a potential tumor suppressor in hepatocellular carcinoma. Clin Cancer Res. (2011) 17:6693-701. doi: 10.1158/1078-0432.CCR-10-2774

26. Meng X, Brachova P, Yang S, Xiong Z, Zhang Y, Thiel KW, et al. Knockdown of MTDH sensitizes endometrial cancer cells to cell death induction by death receptor ligand TRAIL and HDAC inhibitor LBH589 co-treatment. PLoS ONE. (2011) 6:e20920. doi: 10.1371/journal.pone.0020920

27. Su P, Zhang Q, Yang Q. Immunohistochemical analysis of Metadherin in proliferative and cancerous breast tissue. Diagn Pathol. (2010) 5:38. doi: 10.1186/1746-1596-5-38

28. Kikuno N, Shiina H, Urakami S, Kawamoto K, Hirata H, Tanaka Y, et al. Knockdown of astrocyte-elevated gene-1 inhibits prostate cancer progression through upregulation of FOXO3a activity. Oncogene. (2007) 26:7647-55. doi: 10.1038/sj.onc.1210572

29. Luo L, Tang H, Ling L, Li N, Jia X, Zhang Z, et al. LINC01638 IncRNA activates MTDH-Twist1 signaling by preventing SPOP-mediated c-Myc degradation in triple-negative breast cancer. Oncogene. (2018) 37:616679 doi: 10.1038/s41388-018-0396-8

30. Liang Y, Hu J, Li J, Liu Y, Yu J, Zhuang X, et al. Epigenetic activation of TWIST1 by MTDH promotes cancer stem-like cell traits in breast cancer. Cancer Res. (2015) 1 75:3672-80. doi: 10.1158/0008-5472.CAN-15-0930

31. Du C, Yi X, Liu W, Han T, Liu Z, Ding Z, et al. MTDH mediates trastuzumab resistance in HER2 positive breast cancer by decreasing PTEN expression through an NFkappaB-dependent pathway. BMC Cancer. (2014) 14:869. doi: 10.1186/1471-2407-14-869

32. Tokunaga E, Nakashima Y, Yamashita N, Hisamatsu Y, Okada S, Akiyoshi S, et al. Overexpression of metadherin/MTDH is associated with an aggressive phenotype and a poor prognosis in invasive breast cancer. Breast Cancer. (2014) 21:341-9. doi: 10.1007/s12282-012-0398-2

33. Liao W-T, Guo L, Zhong Y, Wu Y-H, Li J, Song L-B. Astrocyte elevated gene-1 (AEG-1) is a marker for aggressive salivary gland carcinoma. J Transl Med. (2011) 9:205. doi: 10.1186/1479-5876-9-205

34. El-Serag HB, Rudolph KL. Hepatocellular carcinoma: epidemiology and molecular carcinogenesis. Gastroenterology. (2007) 132:2557-76. doi: 10.1053/j.gastro.2007.04.061

35. Ahn S, Hyeon J, Park C-K. Metadherin is a prognostic predictor of hepatocellular carcinoma after curative hepatectomy. Gut Liver. (2013) 7:206. doi: $10.5009 /$ gnl.2013.7.2.206

36. Gong Z, Liu W, You N, Wang T, Wang X, Lu P, et al. Prognostic significance of metadherin overexpression in hepatitis B virus-related hepatocellular carcinoma. Oncol Rep. (2012) 27:2073-9. doi: 10.3892/or.2012.1749

37. Gnosa S, Shen Y-M, Wang C-J, Zhang H, Stratmann J, Arbman G, et al. Expression of AEG-1 mRNA and protein in colorectal cancer patients and colon cancer cell lines. J Transl Med. (2012) 10:109. doi: 10.1186/1479-5876-10-109

38. Hui A, Bruce JP, Alajez NM, Shi W, Yue S, Perez-Ordonez B, et al. Significance of dysregulated metadherin and miR-375 in head and neck cancer. Clin Cancer Res. (2011) 17:7539-50. doi: 10.1158/1078-0432.CCR-11-2102

39. Du Y, Jiang B, Song S, Pei G, Ni X, Wu J, et al. Metadherin regulates actin cytoskeletal remodeling and enhances human gastric cancer metastasis via epithelial-mesenchymal transition. Int J Oncol. (2017) 51:63-74. doi: 10.3892/ijo.2017.4002

40. Yao Y, Gu X, Liu H, Wu G, Yuan D, Yang X, et al. Metadherin regulates proliferation and metastasis via actin cytoskeletal remodelling in nonsmall cell lung cancer. Br J Cancer. (2014) 111:355-64. doi: 10.1038/bjc. 2014.267

41. Gatenby R, Brown J. The evolution and ecology of resistance in cancer therapy. Cold Spring Harb Perspect Med. (2018) 8:a033415. doi: 10.1101/cshperspect.a033415

42. Dagogo-Jack I, Shaw AT. Tumour heterogeneity and resistance to cancer therapies. Nat Rev Clin Oncol. (2018) 15:81-94. doi: 10.1038/nrclinonc.2017.166

43. Xu C, Kong X, Wang H, Zhang N, Kong X, Ding X, et al. MTDH mediates estrogen-independent growth and tamoxifen resistance by down-regulating PTEN in MCF-7 breast cancer cells. Cell Physiol Biochem. (2014) 33:1557-67. doi: 10.1159/000358719

44. Meng X, Thiel KW, Leslie KK. Drug resistance mediated by AEG-1/MTDH/LYRIC. Adv Cancer Res. (2013) 120:135-57. doi: 10.1016/B978-0-12-401676-7.00005-X

45. Zhang J, Zhang Y, Liu S, Zhang Q, Wang Y, Tong L, et al. Metadherin confers chemoresistance of cervical cancer cells by inducing autophagy and activating ERK/NF-кB pathway. Tumor Biol. (2013) 34:2433-40. doi: 10.1007/s13277-013-0794-Z

46. Liu H, Song X, Liu C, Xie L, Wei L, Sun R. Knockdown of astrocyte elevated gene-1 inhibits proliferation and enhancing chemo-sensitivity to cisplatin or doxorubicin in neuroblastoma cells. J Exp Clin Cancer Res. (2009) 28:19. doi: 10.1186/1756-9966-28-19

47. Qian B-J, Yan F, Li N, Liu Q-L, Lin Y-H, Liu C-M, et al. MTDH/AEG-1-based DNA vaccine suppresses lung metastasis and enhances chemosensitivity to doxorubicin in breast cancer. Cancer Immunol Immunother. (2011) 60:88393. doi: 10.1007/s00262-011-0997-3

48. Song Z, Wang Y, Li C, Zhang D, Wang X. Molecular Modification of Metadherin/MTDH impacts the sensitivity of breast cancer to doxorubicin. PLoS ONE. (2015) 10:e0127599. doi: 10.1371/journal.pone.0127599

49. Svoronos AA, Engelman DM, Slack FJ. OncomiR or tumor suppressor? The duplicity of MicroRNAs in cancer. Cancer Res. (2016) 76:3666-70. doi: 10.1158/0008-5472.CAN-16-0359

50. Reddy KB. MicroRNA (miRNA) in cancer. Cancer Cell Int. (2015) 15:38. doi: 10.1186/s12935-015-0185-1

51. Liu Y, Kong X, Li X, Li B, Yang Q. Knockdown of metadherin inhibits angiogenesis in breast cancer. Int J Oncol. (2015) 46:2459-66. doi: 10.3892/ijo.2015.2973

52. Zhou C-X, Wang C-L, Yu A-L, Wang Q-Y, Zhan M-N, Tang J, et al. MiR630 suppresses breast cancer progression by targeting metadherin. Oncotarget. (2016) 7:1288. doi: 10.18632/oncotarget.6339

53. Dong R, Liu X, Zhang Q, Jiang Z, Li Y, Wei Y, et al. miR-145 inhibits tumor growth and metastasis by targeting metadherin in high-grade serous ovarian carcinoma. Oncotarget. (2014) 5:10816-29. doi: 10.18632/oncotarget.2522

54. Zhang S, Liu L, Lv Z, Li Q, Gong W, Wu H. MicroRNA-342-3p inhibits the proliferation, migration, and invasion of osteosarcoma cells by targeting astrocyte-elevated gene-1 (AEG-1). Oncol Res Featur Preclin Clin Cancer Ther. (2017) 25:1505-15. doi: 10.3727/096504017X148864854 17426

55. Hu K, Mu X, Kolibaba H, Yin Q, Liu C, Liang X, et al. Metadherin is an apoptotic modulator in prostate cancer through miR-342-3p regulation. Saudi J Biol Sci. (2018) 25:975-81. doi: 10.1016/j.sjbs.2018.04.015

56. Liu P, Tang $\mathrm{H}$, Chen $\mathrm{B}$, He Z, Deng $\mathrm{M}$, Wu $\mathrm{M}$, et al. miR-26a suppresses tumour proliferation and metastasis by targeting metadherin in triple negative breast cancer. Cancer Lett. (2015) 357:384-392. doi: 10.1016/j.canlet.2014.11.050 
57. Tang Y, Liu X, Su B, Zhang Z, Zeng X, Lei Y, et al. microRNA-22 acts as a metastasis suppressor by targeting metadherin in gastric cancer. Mol Med Rep. (2015) 11:454-460. doi: 10.3892/mmr.2014.2682

58. Gu C, Feng L, Peng H, Yang H, Feng Z, Yang Y. MTDH is an oncogene in multiple myeloma, which is suppressed by Bortezomib treatment. Oncotarget. (2016) 7:4559-69. doi: 10.18632/oncotarget.6610

59. Chen X, Dong K, Long M, Lin F, Wang X, Wei J, et al. Serum anti-AEG1 auto-antibody is a potential novel biomarker for malignant tumors. Oncol Lett. (2012) 4:319-23.doi: 10.3892/ol.2012.734

60. Dhiman G, Lohia N, Jain S, Baranwal M. Metadherin peptides containing $\mathrm{CD} 4+$ and $\mathrm{CD} 8+\mathrm{T}$ cell epitopes as a therapeutic vaccine candidate against cancer. Microbiol Immunol. (2016) 60:646-52. doi: 10.1111/1348-0421.12436
Conflict of Interest Statement: The authors declare that the research was conducted in the absence of any commercial or financial relationships that could be construed as a potential conflict of interest.

Copyright (C) 2019 Dhiman, Srivastava, Goyal, Rakha, Lothion-Roy, Mongan, Miftakhova, Khaiboullina, Rizvanov and Baranwal. This is an open-access article distributed under the terms of the Creative Commons Attribution License (CC BY). The use, distribution or reproduction in other forums is permitted, provided the original author(s) and the copyright owner(s) are credited and that the original publication in this journal is cited, in accordance with accepted academic practice. No use, distribution or reproduction is permitted which does not comply with these terms. 